\title{
The robotics market: development prerequisites, features and prospects
}

\author{
Olga Digilina ${ }^{1, *}$, and Irina Teslenko ${ }^{2}$ \\ ${ }^{1}$ RUDN -University, Miklukho-Maklaya str.6, 117198 Moscow, Russia \\ ${ }^{2}$ Vladimir state university, Gorky Street, 87, 600000 Vladimir, Russia
}

\begin{abstract}
The article is devoted to the peculiarities of the development of the robotics market in Russia and in the world. The authors note that the use of robots in various fields of activity ensures accuracy, productivity, flexibility, rationality in the use of the workspace, economy, etc. These advantages explain the rapid development of the robotics market today. The authors emphasize that Russia has every chance to take a leading position in the promising high-tech markets. Stimulating domestic demand for domestic developments, actively attracting all available sources of investment, taking into account new directions for future breakthrough technologies will help domestic manufacturers to gain competitive positions in the global robotics market.
\end{abstract}

\section{Introduction}

The last two years have been marked by major changes in technology and technology. This was largely facilitated by the pandemic: the demand for automation solutions in the field of remote services, the creation of digital jobs, the use of voice smart assistants, robots, etc. has grown.

Indeed, the dramatic change in the established habits of citizens due to self-isolation has resulted in a growing need for technology upgrades. Stores with an automated shopping system and their own contactless payment services have appeared; online paperwork has become a reality; online cinemas appeared; VR technology, which was previously perceived as nothing more than entertainment, has become one of the indispensable tools in some areas of activity, for example, real estate.

The quality of education has become a serious driver of the advancement of modern technologies. Graduates of universities (including Russian ones) actively demonstrate their competencies, create successful startups that are in demand on the world market.

Technological projects began to appear that are aimed at real market needs and are of interest to investors. This contributed to the revival of venture investment [1]. So the Russian venture capital market almost doubled in 2020: the volume of public transactions with the participation of Russian startups amounted to 21.9 billion rubles. (in 2019 - 11.6 billion), and the number of transactions increased to 180 compared to 134 in 2019. The largest growth was shown by the foreign investment sector, and the largest decline was shown by the state venture, which had been growing successfully in the previous two years [2].

${ }^{*}$ Corresponding author: digilina ob@pfur.ru 
As a result of the ongoing changes, some experts expressed the opinion that a new, sixth technological order with the widespread use of cyber-physical systems has come.

Of course, the above examples are signs of the so-called "smart economy", which is so much talked about in Russia. At the same time, the statement about the formation of a new technological order in the country is still premature.

\section{Methods and types of the Earth's remote sensing}

The object of this work is a set of problems associated with the formation of the robotics market in Russia and abroad. The authors carried out a content analysis of publications on the problems of robotization and digitalization of production processes, studied arrays of statistical information, reports of large companies in the production of industrial robots, Russian state federal and sub-federal programs aimed at stimulating the introduction of robotics into production processes.

All these sources contributed to the identification of problems and institutional traps associated with the introduction of robotic technologies into production processes, and, in this regard, with new realities in emerging in the economy.

\section{Analysis of the development features of the robotics market}

The world owes the emergence of the very concept of "technological order" to the economistscientist N.D. Kondratyev. The technological structure is a set of technologies inherent in a certain production level [3]. The improvement of the scientific and technological base leads to a change in structures.

The development of bio- and nanotechnology, genetic engineering, membrane and quantum technologies, photonics, micromechanics, thermonuclear energy, information and cognitive technologies should ultimately lead to qualitative changes, providing a fundamentally new level of development of socio-economic systems due to a sharp decrease in energy and material consumption of production ...

The contours of the new sixth technological order began to take shape back in 2010, and the maturity phase is expected in the 2040s. Its origin began in the depths of the fifth technological order in countries such as the USA, Japan and China.

According to the General Director of the Institute of Aviation Materials (FSUE "VIAM" of the State Scientific Center of the Russian Federation) Academician of the Russian Academy of Sciences E. Kablov, in the United States at present, the share of the productive forces of the fifth technological order is $60 \%$, the fourth $-20 \%$, and about $5 \%$ falls on the sixth technological order.

In Russia, the share of technologies of the fifth order is still about $10 \%$ (mainly in the military-industrial complex and the aerospace industry), more than $50 \%$ of technologies belong to the fourth, and almost a third - to the third order [4]. The lag behind the leaders is obvious.

In its most general form, the sixth technological mode is the transformation of the technological environment into a complex technosphere with its own behavior, this is the transition of human civilization to a man-machine one.

According to forecasters, the sixth technological order can be implemented in different ways, but all researchers agree that it will be based on robotics: the direction of development of information and communication technologies will change - instead of the "Gibson approach" (computers, networks, virtual reality), the "approach Azimova "(robots that will become part of society) [5]. 
The very definition of a robot has not yet been finally fixed. According to P. Krugman, a robot can be considered any object that uses technology to perform work that was previously left to people [6].

Most experts name two main properties of a robot: autonomy in performing the assigned task and the ability to independently respond to ongoing changes. Only such an object is really capable of replacing a person in various spheres of labor activity [7].

The benefits of using robots are undeniable. It:

1. Ensuring high quality products (even if the work is hard, boring and monotonous).

2. Minimization of rejects (robots do not get tired, and motion sensors and vision systems allow minimizing the number of rejects).

3. Accuracy and repeatability of processing (robots can perform tasks that are beyond human control) [8].

4. Versatility (the robot can work anywhere - in a factory, in an office, in the field, underground, in the air: only working tools and basic algorithms will differ).

5. Cost reduction (according to the McKinsey Global Institute, the reduction in operating costs due to automation in each of the sectors of the economy can currently range from 15 to $30 \%$ [7]).

6. Reducing the risk of injury (robots can work painlessly in hazardous areas).

It is no accident that when they talk about robots, they turn to the $4 \mathrm{D}$ formula: Dull, Dirty, Dangerous, Dear (routine, dirty, dangerous and expensive work) [9].

In 2020, the danger of coronavirus infection became relevant, in response to this, the developers had various options for solving the problem using robotics: the use of drones for disinfection, mobile robots informing about the need to observe social distance, courier robots, automated testing of people for COVID- 19, etc.

At the same time, the debate about the shortcomings of robotization does not subside. Among them are called:

- reduction of workers (the World Economic Forum (WEF) predicts the loss of 75 million jobs by 2022; in one retail alone, robots will replace more than 7 million workers within 10 years [9]),

- rigid dependence on the computer system,

- complex control in extreme situations (in the event of a breakdown, power surges or other unforeseen situations, it will be difficult to quickly restore the workflow),

- limited diversification (most robots are capable of performing no more than 1-2 operations simultaneously [8]),

- lack of a creative approach in the process of activity.

Many of these shortcomings are associated with unresolved technical and technological issues. As for the unemployment caused by replacing workers with robots, there is another opinion on this matte.

Practice shows that the introduction of automatic machines is rather slow, not revolutionary, but evolutionary, and unevenly across the branches of the economy. During this time, a generation of people, their habits and attitudes are changing: young people no longer want to work at the machine, to be cashiers, loaders, janitors. They want other professions. And such professions appear in connection with the ongoing changes.

The very business model of enterprises is changing. By introducing robots, businesses are becoming more cost-effective. By cutting costs through the use of robots, they can manipulate the price. By reducing it, they attract more and more consumers, increasing their market share. And this requires an increase in production - accordingly, additional workers are involved. In addition, robotization presupposes the presence of those workers who will create, improve robots and control their activities. In this sense, the introduction of robots does not directly lead to unemployment. 
On the other hand, if enterprises do not implement modern technologies, they will begin to lose their competitive positions, give up their market share to advanced companies, and eventually curtail production and lay off workers. This scenario seems to be quite unattractive, given that robotization is objectively inevitable, and the robotics market has been developing for more than a decade.

Currently, there are several segments in the robotics market. It:

1. Industrial robots that perform all kinds of work (welding, painting, assembly, lifting, metal processing, quality control, etc.). In this segment, there are not only companies that: produce robots. There are companies that manufacture or supply various components for robots; create robotic complexes (RTC) and integrate them into production; develop software for robots; make service. Manufacturing industrial robots is only a third of a complete robotic solution.

2. Service robotics. Service robots are produced for both personal use and business, differing in price and quality. Here, too, there are companies that produce equipment, robotic kits, and there are companies that provide services based on ready-made kits [10].

This is the fastest growing segment currently. Its development is due to the high cost of labor, a lack of qualified personnel, an increase in investment in research and development, and an increase in demand for automation among all economic entities.

According to the estimates of the research company ResearchAndMarkets, the volume of the global robot market in 2019 reached $\$ 34$ billion. The automotive industry accounted for the largest share of the industrial robot market (about 32\%) [11].

In five years (2014-2019), the global growth in robot sales was approximately $85 \%$. The World Robotics 2020 report indicates that 373,000 industrial robots were installed worldwide in $2019,12 \%$ less than in 2018 . At the same time, the total volume of manipulators used in factories reached 2.7 million, an increase of $12 \%$ more than in 2018 [12].

Asia and Australia are the fastest growing industrial robot markets. In 2019, these regions accounted for over $67 \%$ of the industrial robotics market. Overall, the five main markets (China, Japan, the Republic of Korea, the United States and Germany) accounted for about $75 \%$ of total robotics sales in 2019 . The second leading region in the industrial robotics market was Europe, and the third was America.

The global market for service robots in 2019 was valued at more than $\$ 17$ billion.

As for Russia, in the sector of production and use of industrial robots, it loses to many countries. The density of robotization at domestic enterprises in 2019 did not exceed 5 robots per 10 thousand employees, with the world average of 112. In the most developed countries, this figure was many times higher: 228 - in the USA, 346 - in Germany and 918 - in Singapore [13].

According to the International Federation of Robotics (IFR) for 2019, Russia unexpectedly took second place in the world ranking of manufacturers of service robots. In this area, Russia has great potential: the country produces robotic assistants, robotic couriers, robotic navigators, robotic prostheses (for example, cybernetic arms), etc.

There are 889 manufacturers of service robots in the world, in Russia there are 73 of them. The USA has 223 companies. Russia is followed in the ranking by Germany (69), China (64), France (52) and Japan (50). Experts explain Russia's second place in the rating by the large number of small effective startups.

Nowadays, medical service robots are in demand everywhere. Service robots are actively used in agriculture and in everyday life (robotic vacuum cleaners, robots for mowing lawns, etc.). A large number of them are produced in the USA (75\%).

Russia not only produces, but also exports service robots (for example, in 2020 the Promobot company supplied robots to the UAE police service and to the Istanbul airport) [13]. 
Self-driving vehicles (unmanned aerial vehicles) and exoskeletons for various purposes are among the most promising areas for the development of domestic robotics.

The service robot carries more complex functionality: it requires flexibility, the ability to quickly adapt to changing environment. All of this involves significant development effort and other funding from investors as opposed to building an industrial robot.

Sberbank experts believe that the needs for industrial robotics will soon be met, while the service sector will continue to provide a variety of options for the development and implementation of autonomous systems [7].

In general, despite certain successes, the Russian robotics market is occupied by foreign manufacturers who have many years of experience in this area.

Due to the lack of an established ecosystem for the production of robots, difficulties for Russian manufacturers begin already at the stage of searching for components - most of them have to be ordered abroad. Problems with production, lack of investment and insufficient demand restrain the expansion of the domestic domestic market for robotics, its developers are forced to focus mainly on foreign markets [9].

In terms of the density of robotization (the number of robots per 10,000 workers), there are 6 robots per 10,000 workers in Russia. On average, this figure in the world is more than 100, in South Korea - more than 700 or 800 robots per 10,000 workers, in China - about 130 per 10,000 workers [9].

According to experts, only 5,000 robots are currently in operation in the Russian industry. To get closer to global indicators, there should be 20 times more robots $-100,000$ units. To service them, 20,000 specialists are required, but for now there are a little more than 1,000 people in the whole country. By 2025, this need will increase to 40,000 specialists, and by 2030 - to $66,000$.

According to a study by Gazpromneft, the oil and gas sector alone will require about a million robots by 2030 . Currently, according to the leadership of the NAURR, the segment of domestic industrial robotics is growing by about $40 \%$. The trend will continue in the coming years.

In the segment of service robots, the market for educational robotics is growing most dynamically. Many niches of the service robots market are not yet occupied, so Russian companies have a chance to start competing with foreign manufacturers [14].

According to IDC, the global industrial robotics market in 2022 will exceed \$ 210 billion. The global market for personal service robots is projected at $\$ 2$ billion in 2021 [7] And this is not the limit.

Experts name the directions in which new technological breakthroughs can be expected for the development of the robotics market. It:

1. New element base (development of microelectronics: microcircuits based on a new semiconductor material of gallium nitride will significantly reduce the cost of industrial robots and stimulate the automation of heavy industries).

2. New batteries (the introduction of long-life lithium-ion batteries will reduce operating costs and make advanced technology available to different customers).

3. Integration of robots into traditional production processes (initial design of robots that will work in contact with people, which will reduce capital costs for the inclusion of robots in production, logistics and other economic chains).

4. Machine learning and artificial intelligence (robotic systems with machine learning will be able to master new tasks almost independently, which is especially important for service robots).

Experts predict the formation of a fundamentally new management model as machine learning technology develops. Now it is not the person who creates the algorithm that tells the machine what to do, but the machine (computer) based on Big Data technologies and 
artificial intelligence gives orders to people. Programmers optimize algorithms so that they more effectively control the activities of living workers [6].

\section{Conclusions}

Summing up the overall result, it should be noted that many factors of the external environment in recent years have stimulated dramatic changes in production conditions around the world. They led to the emergence of technologies of the new sixth order. One of its manifestations was the ubiquity of robotic solutions.

The use of robots in various fields of activity ensures accuracy, productivity, flexibility, rationality in the use of the workspace, economy, etc. It is these advantages that explain such a rapid development of the robotics market today.

For a number of reasons, Russia lags behind the leading countries in robotics. Nevertheless, the country has every chance to take its place in the promising high-tech markets. Stimulating domestic demand for domestic developments, actively attracting all available sources of investment, taking into account new directions for future breakthrough technologies will help domestic manufacturers to gain competitive positions in the global robotics market.

\section{References}

1. "Our time has come": how a new technological order is being created (2021) https://www.rbc.ru/

2. Venture capital market in Russia in 2020 (2020) https://incrussia.ru/

3. Technological paradigms - waves and cyclicality (2020) https://viafuture.ru/

4. The sixth technological order (2020) https://www.nkj.ru/

5. S. Pereslegin "Outlines of the sixth technological order" https://imhotype.livejournal.com/

6. Sberbank analyzed the world robotics market - Electronic Time (2021) https://russianelectronics.ru

7. The global robotics market through the eyes of Sberbank (2019) https://www.crn.ru/

8. Robots in the modern world: popular directions of robotization (2021) https://roboschool.pro

9. Invisible revolution: how the pandemic became the "new Chernobyl" for the development of robotics, https://prodonbass.ru

10. Robotics: a business where you need to act now (2020) https://rb.ru/

11. Robotics (world market) (2020) https://www.tadviser.ru

12. How many robots are there in the world? New data on the global robotics market (2020) https://ya-r.ru/

13. Iron helping hand (2020) https://rg.ru/

14. Service robotics is the most developed in the country. Namely, the educational direction, (2020) http://edurobots.ru/ 